\title{
Redescription of Lasioseius cynari Chant, 1963 (Acari: Mesostigmata: Blattisociidae)
}

\author{
Claudia V. Cedola ${ }^{1 凶}$, Maria F. Gugole Ottaviano², João MARTin ${ }^{3}$ and Gilberto J. de Moraes ${ }^{4}$ \\ (Received 19 October 2016; accepted 22 March 2017; published online 04 July 2017; edited by Farid FARAJI) \\ ${ }^{1}$ Centro de Estudios Parasitológicos y de Vectores (CEPAVE) CONICET-CCT La Plata, FCNyM - UNLP. Argentina. \\ (凶) ccedola@fcnym.unlp.edu.ar \\ ${ }^{2}$ Departamento de Evaluación Sensorial de Alimentos (DESA-ISETA) 9 de Julio, Buenos Aires. Argentina. fernanda@desa.edu.ar \\ ${ }^{3}$ Departamento de Entomologia e Acarologia (ESALQ, USP) Piracicaba-SP, Brazil. Joao_ignez@hotmail.com \\ ${ }^{4}$ Departamento de Entomologia e Acarologia (ESALQ, USP) Piracicaba-SP, Brazil. CNPq Researcher, moraesg@usp.br
}

\begin{abstract}
A redescription of adult Lasioseius cynari Chant, 1963 is presented based on the examination of paratype specimens deposited at the Canadian National Collection of Insects and Arachnids, Canada and on specimens from Argentina. The paratype specimens originating from Italy were collected from globe artichokes (Cynara scolymus L.) and the specimens from Argentina were collected from the same host, artichoke thistle (Cynara cardunculus L.), both Asteraceae. This is the first report of this species after its original description, and a new host record of this species on $C$. cardunculus.
\end{abstract}

KEYWORDS - Argentina; Blattisociidae; Lasioseius; description; artichoke

ZOOBANK — 93A3A39F-6AD0-43FC-8B8B-F45588AF21EA

\section{INTRODUCTION}

Lasioseius Berlese is the most diverse genus of Blattisociidae (Karg, 1980; Christian and Karg, 2006; Moraes et al., 2016). It now contains almost 200 species, described especially from tropical regions (Moraes et al., 2016).

Mites of this genus were recently collected from leaves of globe artichoke (Cynara scolymus L.; Asteraceae), one of the typical crops in Los Hornos, and on leaves of Cynara cardunculus L. (artichoke thistle), a wild plant in Villa Elisa, Buenos Aires Province, Argentina. These were identified as Lasioseius cynari Chant, 1963, a species originally described from adult specimens intercepted in quarantine on globe artichokes imported from France, Italy and Turkey to different parts of the USA.

The objective of this paper is to complement the description of L. cynari, based on the examination of type specimens as well as on the specimens collected in Argentina.

\section{MATERIALS AND METHODS}

Paratype specimens (eight females and five males) examined in this study were collected from globe artichokes (C. scolymus L.) imported from Italy to New York, USA, on March 31, 1953; they were loaned from the Canadian National Collection of Insects and Arachnids, Canada (lot 53-6084). Specimens 
from Argentina were collected by M.F. Gugole Ottaviano in Arana $\left(38^{\circ} 52^{\prime} \mathrm{S}, 5^{\circ} 59^{\prime} \mathrm{W}\right)$ from C. scolymus (4 females), by C. Cédola in Los Hornos ( $35^{\circ} 01^{\prime} 20^{\prime \prime} \mathrm{S}$, $57^{\circ} 56^{\prime} 15^{\prime \prime} \mathrm{W}$ ) from C. cardunculus (2 females) and in Villa Elisa $\left(34^{\circ} 51^{\prime} 12^{\prime \prime} \mathrm{S}, 58^{\circ} 04^{\prime} 45^{\prime \prime} \mathrm{W}\right)$ from C. cardunculus (1 female). All the collected specimens were examined under an interference contrast microscope.

Diagnostic structures of the specimens were measured by using a graded ocular. For each character, the average measurement followed (in parentheses) by the minimum and the maximum measurements are given in micrometres. Setal nomenclature is based on Lindquist \& Evans (1965) and Lindquist (1994). Leg setal notation and chaetotactic formulae are based on Evans (1963). Representative specimens of these mites were deposited in División Entomología, Museo de La Plata, Argentina, and in Departamento de Entomologia e Acarologia (ESALQ, USP) Piracicaba-SP, Brazil.

\section{RESUlts}

\section{Lasioseius cynari Chant, 1963 Figures 1-5}

Lasioseius cynari Chant, 1963: 286 Lasioseius cynari - Lindquist, 1964: 317; Farrier \& Hennessey, 1993: 36; Moraes et al., 2016: 165. Lasioseius (Crinidens) cynari - Christian \& Karg; 2006: 161

Diagnosis of adult females: dorsal shield reticulate and punctate, with 36 pairs of setae including $r 2-r 4$; with eight pairs of marginal setae $(r-R)$ on unsclerotized lateral cuticle; sub marginal setae ( UR) absent. Setae r3, Z3- Z5, S4 and S5 moderately long and lanceolate; other setae short, usually less than half as long as distance to respective subsequent setae. Ventrianal shield with six pairs of opisthogastric setae in addition to circumanal setae. With 2-3 pairs of opisthogastric setae on unsclerotized cuticle around ventrianal shield (Jv5 and Zv1; Zv5 present or absent). Calyx of spermatheca tubular; major duct broad, bladder-shaped. Fixed and movable cheliceral digits respectively with ca. five and three teeth in addition to apical tooth. Epistome with three anterior extensions. Legs without macrosetae.

\section{Description}

\section{Adult female (Figures 1-3)}

(5 paratypes and 5 specimens from Argentina measured).

Dorsal idiosoma (Figure 1A) - Dorsal shield strongly reticulate, punctuate behind j3, 490 (475-500) long and 259 (250-265) wide at level of $r 3$. Podonotal region of dorsal shield with 21 pairs of setae $(j 1-j 6, z 1-z 6, s 1-s 6, r 2-r 4), 12$ pairs of lyrifissures and three pairs of gland pores. Opisthonotal region with 15 pairs of setae ( J1-J5, Z1-Z5, S1-S5), eight pairs of lyrifissures and three pairs of pores. Setae r3, Z3-Z5, S4 and S5 moderately long and lanceolate (Figure 2C); the first smooth and others distally serrate; other setae aciculate and short, usually less than half as long as distance to respective subsequent setae. Unsclerotized cuticle laterad of dorsal shield with eight pairs of marginal setae of similar lengths and shape (r5-r6, R1-R6), r5 in some specimens very close to shield margin; sub marginal setae ( $U R$ ) absent; with a lyrifissure between $R 3-R 4$ $(R p)$. Measurements of dorsal setae shown in (Table 1).

Ventral idiosoma (Figure 1B) - Setae aciculate and smooth, except JV5, lanceolate, stout and distally serrate. Base of tritosternum 25 long and 10 (10-11) wide at median length; laciniae free for about $83 \%$ of their total length. Pre-sternal plates reticulate. Sternal shield punctuate, 98 (97-99) long and 81 (80-83) wide at level st2; posterior margin slightly concave; with three pairs of sternal setae (st1-st3) and two pairs of lyrifissures. Metasternal plate rounded, bearing st4 and lyrifissure $i v 5$. Epigynial shield 126 (124-130) long, including anterior hyaline flap, punctuate, bearing genital seta (st5); paragenital lyrifissure on unsclerotized cuticle posterolaterad of genital seta. Four elongate transversely aligned platelets between epigynal and ventrianal shields; sometimes apparently fused into a single line. Two pairs of punctuate metapodal plates, the inner rounded and much smaller than 
TABLE 1: Comparative measurements $(\mu \mathrm{m})$ of characters of female and male of Lasioseius cynari, mean (min-max); $\mathrm{n}=10$ females $(5$ paratypes and 5 from Argentina) and 5 males (paratypes).

\begin{tabular}{|c|c|c|c|}
\hline \multirow[b]{2}{*}{ Structures } & \multicolumn{2}{|c|}{ Paratypes } & \multirow{2}{*}{$\frac{\text { Argentinian specimens }}{\text { Female }}$} \\
\hline & Female & Male & \\
\hline Dorsal shield length & $499(488-513)$ & $442(430-460)$ & $490(475-500)$ \\
\hline Dorsal shield width & $284(275-293)$ & $271(263-283)$ & $287(280-300)$ \\
\hline j1 & $18(18-20)$ & $16(13-18)$ & $19(17-20)$ \\
\hline j2 & $17(15-18)$ & $19(18-20)$ & $18(16-19)$ \\
\hline$j 3$ & $17(15-18)$ & $17(13-20)$ & $17(16-18)$ \\
\hline j4 & $14(13-15)$ & $16(13-20)$ & $14(14-14)$ \\
\hline$j 5$ & $15(13-18)$ & $15(15-20)$ & $13(13-13)$ \\
\hline j6 & $17(15-18)$ & $14(15-18)$ & $14(13-14)$ \\
\hline$z^{1}$ & $11(10-13)$ & $9(8-10)$ & $9(8-9)$ \\
\hline$z^{2}$ & $15(13-15)$ & $16(13-18)$ & $15(14-16)$ \\
\hline $2^{3}$ & $15(15-18)$ & $19(18-20)$ & $14(13-15)$ \\
\hline 24 & $17(15-18)$ & $18(13-23)$ & $16(15-17)$ \\
\hline $2^{5}$ & $15(15-15)$ & $12(10-15)$ & $15(14-16)$ \\
\hline $2^{6}$ & $14(13-15)$ & $13(13-13)$ & $13(13-15)$ \\
\hline s1 & $13(13-13)$ & $16(13-18)$ & $13(13-13)$ \\
\hline$s 2$ & $10(8-13)$ & $15(13-18)$ & $9(8-10)$ \\
\hline s3 & $18(18-20)$ & $19(13-23)$ & $13(12-15)$ \\
\hline$s 4$ & $17(15-18)$ & $19(15-20)$ & $14(14-14)$ \\
\hline 55 & $16(15-18)$ & $17(15-20)$ & $16(16-17)$ \\
\hline$s 6$ & $17(15-20)$ & $16(13-18)$ & $13(13-13)$ \\
\hline$r 2$ & $12(10-13)$ & $15(15-15)$ & $13(12-14)$ \\
\hline$r^{3}$ & $55(53-58)$ & $37(35-40)$ & $51(50-51)$ \\
\hline$r 4$ & $14(13-15)$ & $17(13-18)$ & $13(13-14)$ \\
\hline$r 5$ & $14(13-15)$ & $17(15-18)$ & $13(13-14)$ \\
\hline$r 6$ & $12(10-13)$ & $13(13-13)$ & $11(10-11)$ \\
\hline$J 1$ & $14(13-15)$ & $12(10-13)$ & $13(12-14)$ \\
\hline$J 2$ & $13(13-15)$ & $12(10-13)$ & $13(12-14)$ \\
\hline J3 & $14(13-15)$ & $11(10-13)$ & $14(13-15)$ \\
\hline$J 4$ & $11(10-13)$ & $10(10-10)$ & $10(9-11)$ \\
\hline J5 & $7(5-8)$ & $6(5-8)$ & $8(7-9)$ \\
\hline$Z 1$ & $15(13-18)$ & $12(10-13)$ & $13(13-14)$ \\
\hline$Z 2$ & $15(13-15)$ & $13(10-15)$ & $13(12-14)$ \\
\hline$Z 3$ & $42(40-43)$ & $12(10-13)$ & $39(38-40)$ \\
\hline$Z 4$ & $46(47-48)$ & $13(10-15)$ & $44(43-45)$ \\
\hline$Z 5$ & $63(55-68)$ & $49(45-55)$ & $67(65-71)$ \\
\hline
\end{tabular}


TABle 1: Continued.

\begin{tabular}{|c|c|c|c|}
\hline & Paratypes & & Argentinian specimens \\
\hline Structures & Female & Male & Female \\
\hline S1 & $14(13-15)$ & $14(13-15)$ & $14(13-15)$ \\
\hline$S 2$ & $14(13-15)$ & $13(10-15)$ & $13(12-15)$ \\
\hline$S 3$ & $13(13-15)$ & $13(10-15)$ & $13(13-14)$ \\
\hline$S 4$ & $51(50-53)$ & $16(13-18)$ & $48(46-50)$ \\
\hline 55 & $59(55-63)$ & $17(15-20)$ & $60(58-61)$ \\
\hline R1 & $12(10-13)$ & $9(8-10)$ & $11(11-12)$ \\
\hline $\mathrm{R} 2$ & $10(8-13)$ & $9(8-10)$ & $10(10-11)$ \\
\hline R3 & $10(8-13)$ & $11(10-13)$ & $10(9-10)$ \\
\hline R4 & $9(8-10)$ & $10(10-10)$ & $9(9-10)$ \\
\hline R5 & $8(8-10)$ & $9(8-10)$ & $7(6-9)$ \\
\hline R6 & $10(10-10)$ & $8(8-8)$ & $7(7-8)$ \\
\hline$b 1$ & $18(18-23)$ & $12(10-13)$ & $20(19-21)$ \\
\hline b2 & $9(8-10)$ & $8(8-10)$ & $6(5-8)$ \\
\hline b3 & $23(20-25)$ & $15(10-20)$ & $22(21-23)$ \\
\hline Sc & $16(13-18)$ & $17(15-20)$ & $17(16-18)$ \\
\hline$s t 1$ & $17(15-20)$ & $15(13-18)$ & $16(14-17)$ \\
\hline$s t 2$ & $21(20-23)$ & $23(20-25)$ & $19(17-21)$ \\
\hline$s t 3$ & $24(20-25)$ & $24(18-25)$ & $22(20-24)$ \\
\hline$s t 4$ & $23(20-25)$ & $20(18-25)$ & $21(20-22)$ \\
\hline st 5 & $20(20-20)$ & $19(15-23)$ & $21(20-22)$ \\
\hline$J v 1$ & $20(18-23)$ & - & $13(11-15)$ \\
\hline$J v 2$ & $25(23-30)$ & $21(18-23)$ & $23(22-24)$ \\
\hline$J v 3$ & $22(20-25)$ & $26(25-28)$ & 21 (21-21) \\
\hline$J v 4$ & $21(18-23)$ & $22(20-23)$ & $16(16-17)$ \\
\hline$J v 5$ & $51(45-55)$ & $19(18-23)$ & $48(45-50)$ \\
\hline$Z v 1$ & $17(15-18)$ & - & $16(14-18)$ \\
\hline$Z v 2$ & $20(18-23)$ & $19(15-23)$ & $17(15-19)$ \\
\hline$Z v 3$ & $9(8-10)$ & $22(18-25)$ & $9(8-10)$ \\
\hline$Z v 5^{*}$ & - & - & $8(8-10)$ \\
\hline Para-anal & $21(20-23)$ & $19(15-23)$ & $22(22-22)$ \\
\hline Postanal & $27(25-30)$ & $25(23-25)$ & $28(26-31)$ \\
\hline
\end{tabular}

$* Z v 5$ is present in some Argentinian specimens. Therefore, the length of seta was included in table. 

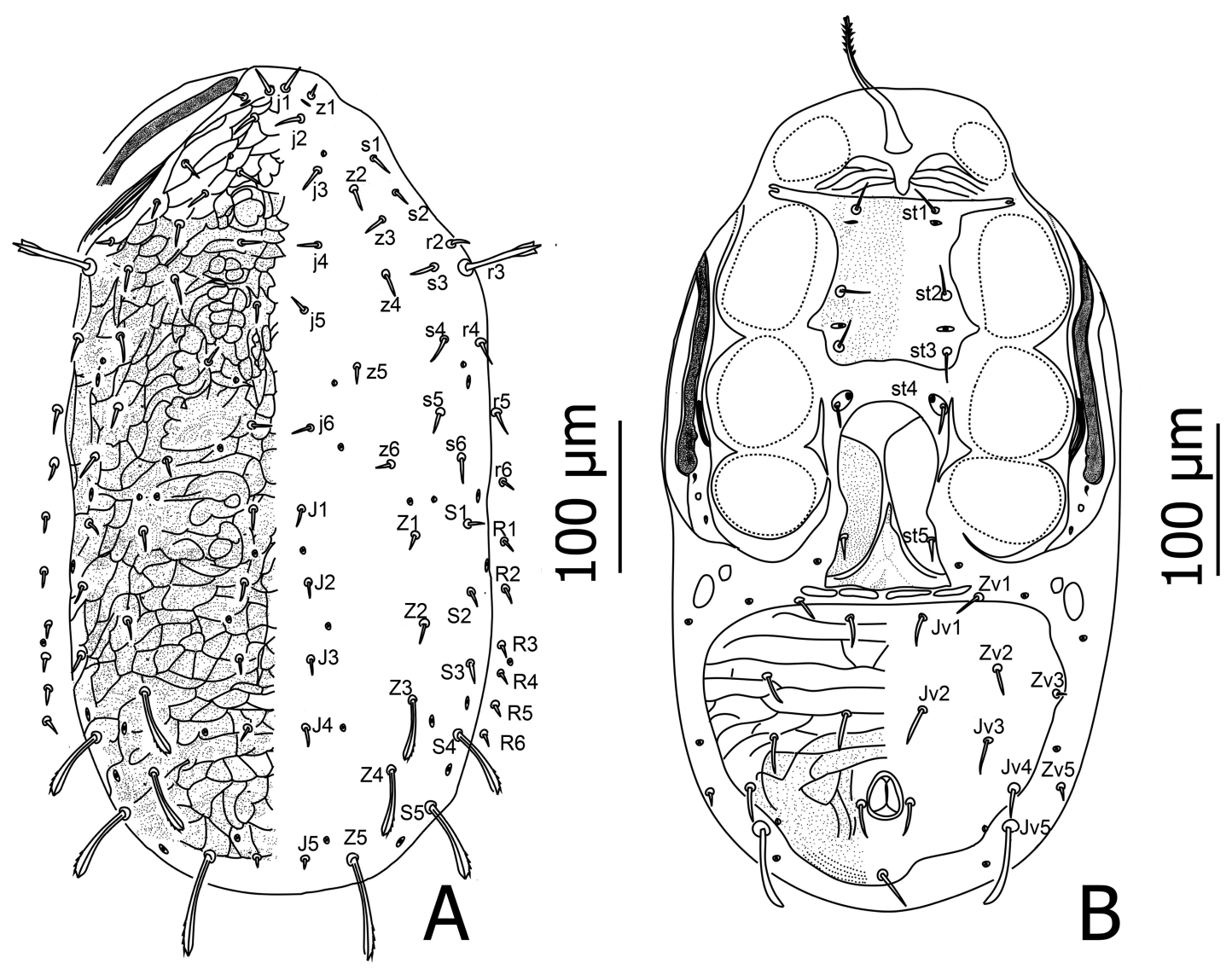

FIGURE 1: Lasioseius cynari, female: A - Dorsal idiosoma, B - Ventral idiosoma.

the subrectangular to oval outer pair. Anterior margin of ventrianal shield of some specimens with a lateral notch near Zv1; ventrianal shield wider 217 (212-225) than long 171 (167-182), reticulate, punctate posteriad of $J v 2$, with six pairs of opisthogastric setae in addition to circumanal setae, one pair of pores posterolaterad of paraanal setae; anal opening not enlarged, 25-27 long including frame. With 2-3 pairs of opisthogastric setae on unsclerotized cuticle around ventrianal shield (Jv5 and Zv1; Zv5 present or absent). Anterior part of endopodal plate fused with sternal shield; part behind sternal shield V-shaped. Exopodal plate distinct, running from posterior margin of coxa IV to region coxa I. Measurements of ventral setae shown in (Table 1).

Peritreme and peritrematic plate (Figure 1B) Peritreme extending anteriorly to base of $z 1$. Peritrematic plate fused with dorsal shield at level of s1 and fused to exopodal shields at level of coxa IV; with a lyrifissure and a pore at level between coxae II-III and two lyrifissures and a pore posteriad of stigma.

Spermathecal apparatus (Figure 2E) - Calyx saccular, major duct inflate, transversely wrinkled, bladder-shaped.

Gnathosoma - Cheliceral shaft length 99 (98-100), excluding basal segment; with distinct dorsal and antiaxial lyrifissures; dorsal seta not distinguishable because of position. Fixed cheliceral digit 30 long, with short setiform pilus dentilis and a row of ca. five teeth in addition to apical tooth (Figure 2B); movable cheliceral digit 28 (28-29) long, with three retrorse teeth in addition to apical tooth. Epistome with three anterior extensions, the median smooth, much shorter than the laterals, which have few denticles on lateral edge (Figure 2D). Deu- 


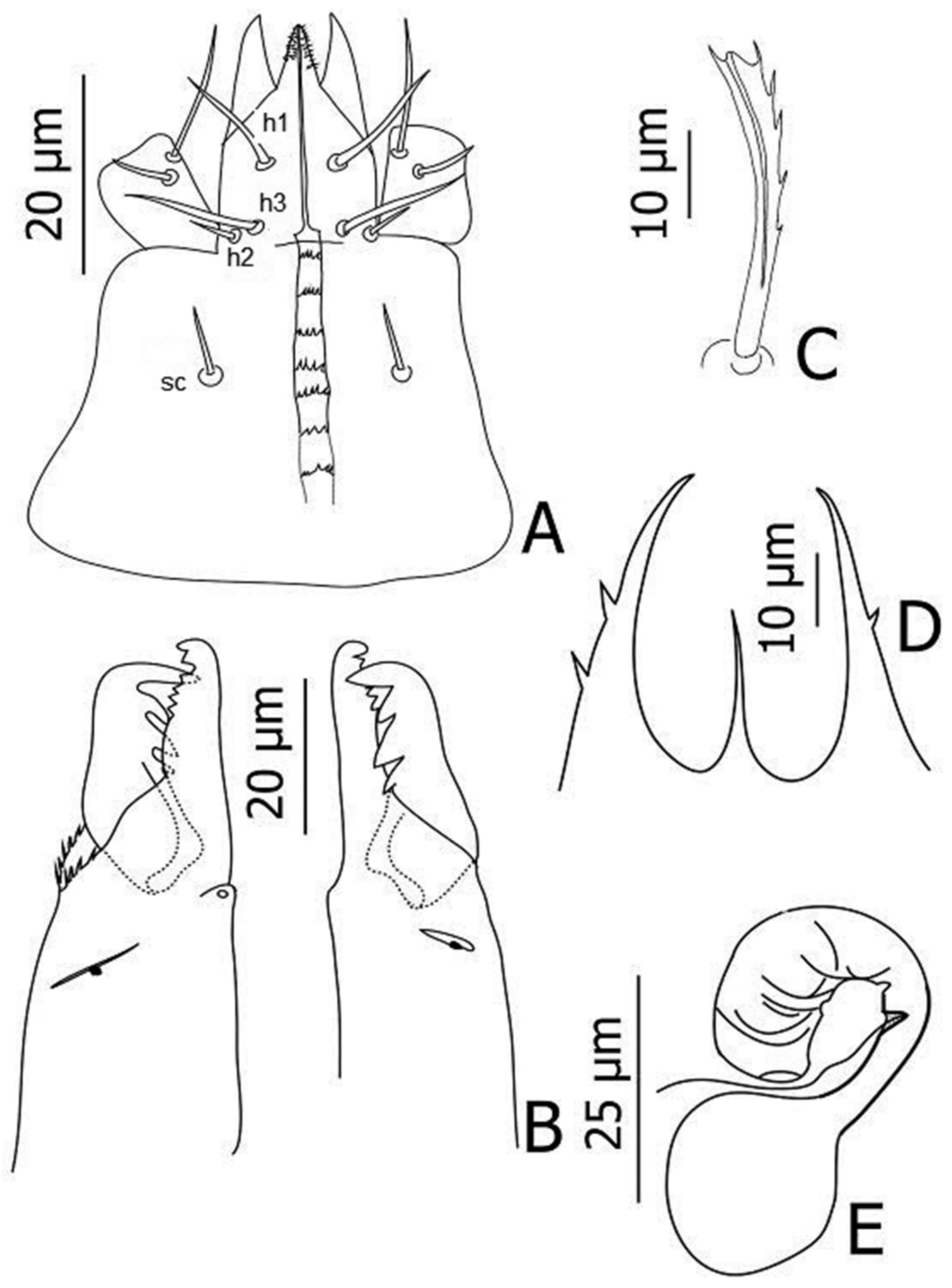

FIGURE 2: Lasioseius cynari, female: A - Ventral gnathosoma, B - View of chelicerae, C - Enlarged view of seta Z5, D - Epistome, F - Spermatheca. 

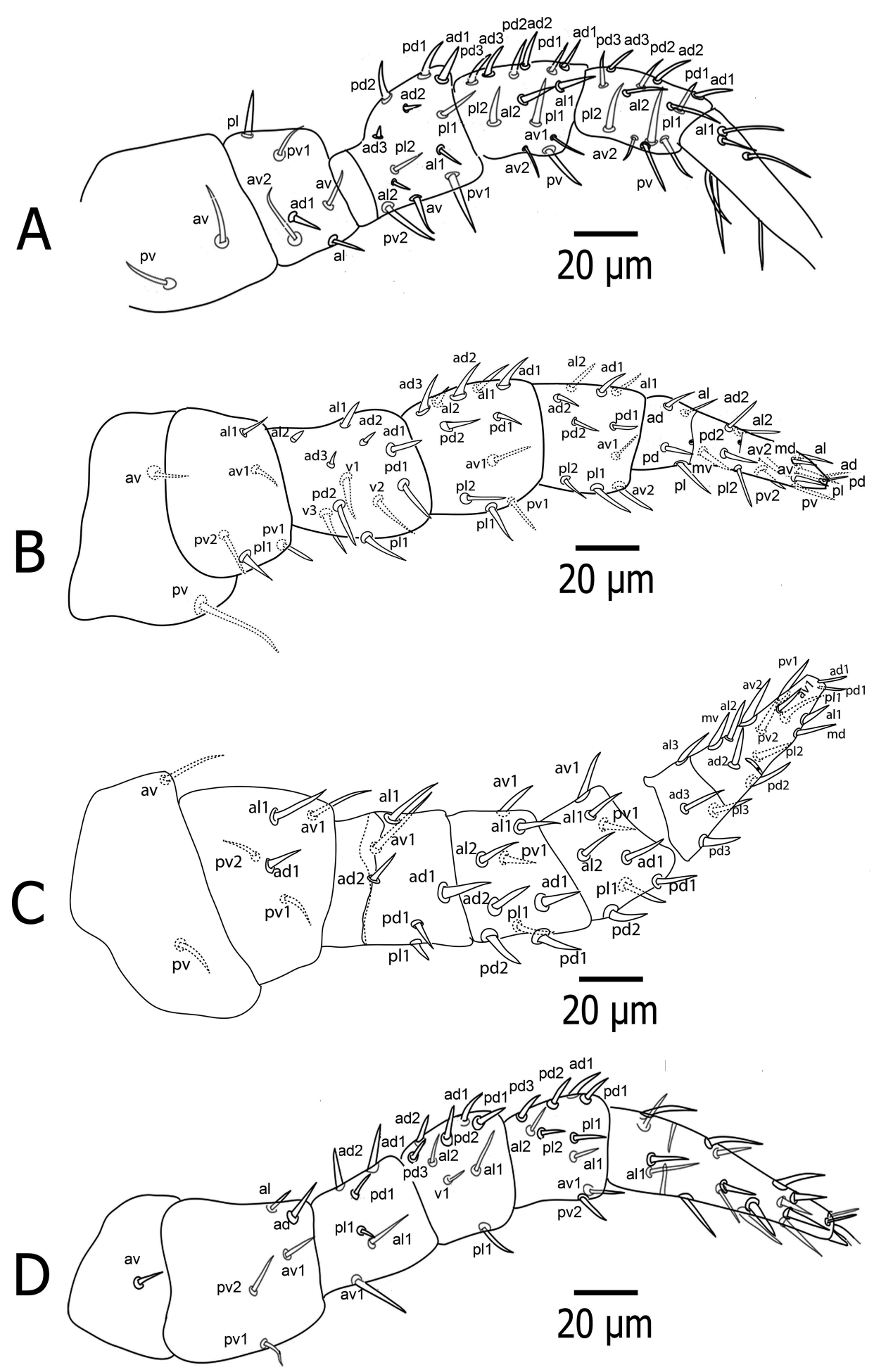

FIGURE 3: Lasioseius cynari, female: A - Leg I, B - Leg II, C - Leg III, D - Leg IV. 
tosternum with distinct lateral lines, with eight transverse lines, of which the first smooth and the subsequent lines with 3-7 denticles each (Figure 2A); palpus 102 (96-109) long, with normal chaetotaxy for the Gamasina as described by Evans (1963); numbers of setae from trochanter to tarsus: 2, 5, 6, 14, 15; apotele two-tined. Subcapitular setae aciculate; $h 1$ and $h 3$ of similar lengths, longer than h2. Corniculi horn-shaped, subparallel to each other. Measurements of setae shown in (Table 1).

Legs (Figure 3A-D) - Legs I-IV with paired claws and pulvillus with three rounded lobes, inserted on well-developed pretarsi. Lengths (excluding pre-tarsus): I: 345 (343-347); II: 334 (331-339); III 320 (318-321); IV: 387 (372-395). Setae aciculate; posterior seta on coxae I and II and anterior seta of coxa III distinctly longer than other coxal setae. Leg I: trochanter: 1,1/0,2/1,1; femur: 2,3/2,2/2,1; genu: 2,3/2,3/1,2; tibia: 2,3/2,3/1,2; Leg II: trochanter: 1,1/0,2/0,1; femur: 2,3/1,2/2,1; genu: 2,3/1,2/1,2; tibia: 2,2/1,2/1,2; Leg III: trochanter: 1,1/2,0/1,0; femur: 1,2/0,1/1,1; genu: 2,2/1,2/1,1; tibia: 2,1/1,2/1,1 and Leg IV: trochanter: $1,1 / 1,1 / 0,1$; femur: $1,2 / 1,1 / 0,1$; genu: 2,2/1,3/0,1; tibia: 2,1/1,3/1,2.

\section{Adult male (Figures 4-5) \\ (5 paratypes measured).}

Dorsal idiosoma (Figure 4A) - Dorsal shield 442 (430-460) long and 271 (263-283) wide, ornamentation similar to female. Podonotal region of dorsal shield with 23 pairs of setae $(j 1-j 6, z 1-z 6, s 1-s 6$; $r 2-r 6)$, and the same complement of lyrifissures and pores as female. Opisthonotal region with 15 pairs of setae ( J1-J5, Z1-Z5, S1-S5), and same complement of lyrifissures and pores as female. Form and relative lengths of dorsal shield setae as in female, except that Z3- Z4 and S4- S5 are short and aciculate. Unsclerotized cuticle laterad of dorsal shield with six pairs of setae $(R 1-R 6)$ and one pair of lyrifissures $(R p)$; setae similar to each other, short and aciculate; sub marginal setae ( UR) absent. Measurements of dorsal setae as in (Table 1).

Ventral idiosoma (Figure 4B) - Shape of setae as in female. Base of tritosternum 17 (10-23) long and 10 (10-11) wide at median length; laciniae free for about $74 \%$ of their total length. Presternal area transversely striate; sternogenital shield 189 (180-198) long and 65 (55-75) wide at level st2; with scant reticulation near lateral margin and behind st4, with five pairs of setae and three pairs of lyrifissures, lineated in region between st4-st5. Ventrianal shield 167 (155-180) long, 225 (215-233) wide, covering most of opisthogaster, not fused with peritrematic and sternogenital shields; ornamentation similar to female, with six pairs of setae (Jv2-Jv5, $\mathrm{Zv2}, \mathrm{Zv3}$ ) in addition to circumanal setae. Postanal seta slightly longer than para-anal seta. Seta $J v 5$ on unsclerotized cuticle. Endopodal plate fused with sternogenital shield. Exopodal plate as in adult female. Measurements of setae shown in (Table 1).

Peritreme and peritrematic plate - Peritreme as in adult female. Peritrematic plate fused with dorsal plate at level between s1-s2 and to exopodal shield al level of anterior margin of coxa IV.

Gnathosoma - Dorsal and antiaxial lyrifissures as well as dorsal seta distinct. Fixed cheliceral digit 25 long, with setiform pilus dentilis and five teeth in addition to apical tooth; movable cheliceral digit 30 long with a single retrorse tooth in additional apical tooth. Spermatodactyl 25 long with slight apical swelling (Figure 5A). Epistome similar to that of female except that median process is relatively slightly longer and has a tooth on each side (Figure 5B). Deutosternal with eight transverse lines; the first smooth and the subsequent with 5-8 denticles each. Corniculi subparallel to each other, slightly more widely spaced and slender, and distally curved (Figure 5C). Palpal chaetotaxy and shape of subcapitular setae as in female; $h 1$ and $h 3$ of similar lengths, longer than $h 2$. Measurements of setae in shown in (Table 1).

Legs - Legs I-IV with claws, pulvilli, pretarsi, shape of setae and chaetotaxy as in female. Length (excluding pre-tarsus): I: 282, II 227; III: 225, IV: 332. Tarsus II with $a v, a v 2$ and $p v 1$ dimorphically spinelike (Figure 5D).

Note - The present work complements a detailed redescription of $L$. cynari given by Lindquist (1964), especially in what refers to the provision of measurements and full illustration of the specimens 

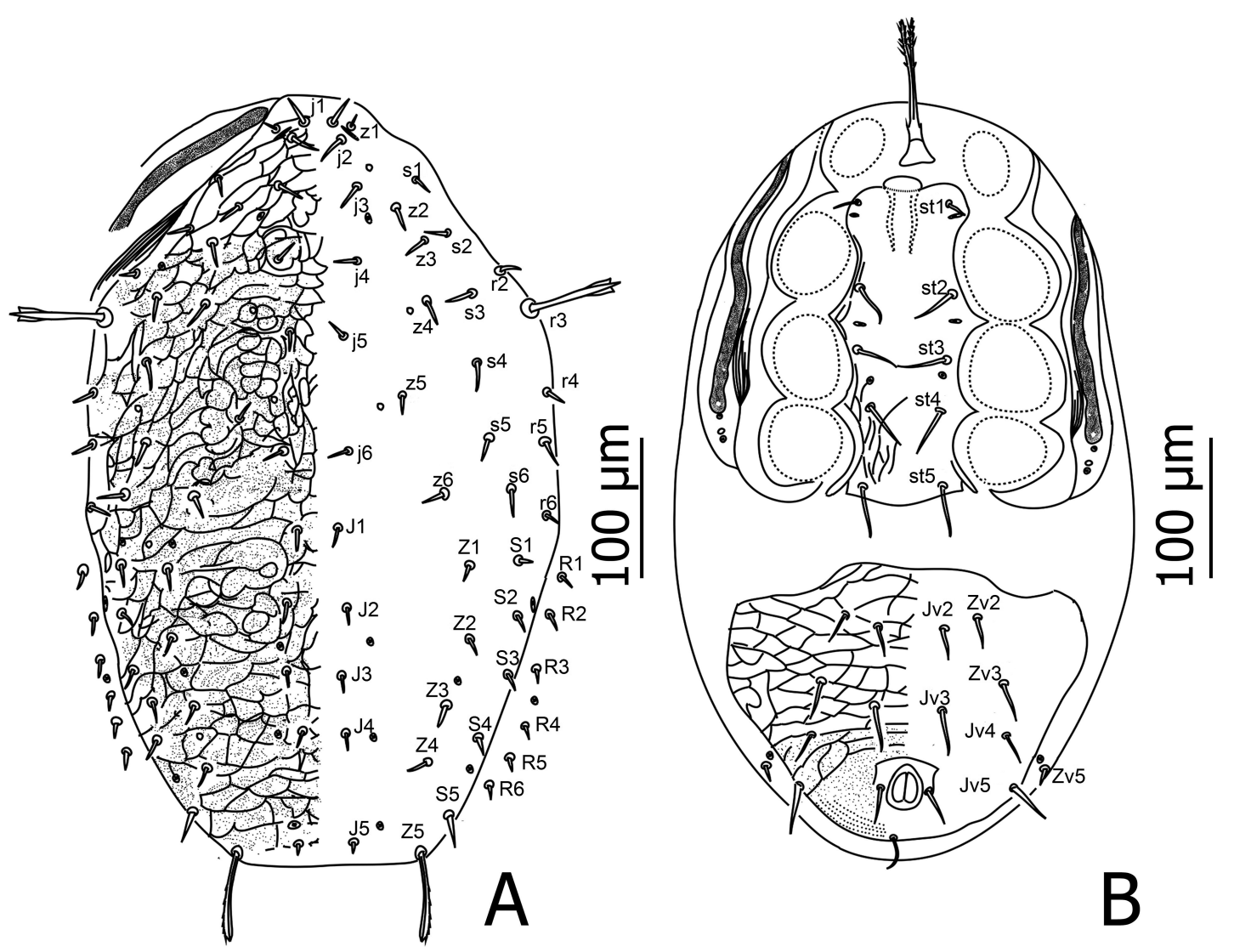

FIGURE 4: Lasioseius cynari, male: A - Dorsal idiosoma, B - Ventral idiosoma.

of both sexes. For both sexes, the characteristics reported in this work fit well those reported by that author, except for the number of cheliceral teeth in females; Lindquist (1964) mentioned only three and two teeth on fixed and movable digits (in addition to the respective apical tooth), instead of ca. five and three, respectively, observed in the present study. In the original description, Chant (1963) does not state the number of teeth, but his illustration seems to show two teeth on each digit. Those differences could be due to the unsuitable angle of the cheliceral digits in the study of those authors.

\section{DISCUSSION}

All type specimens of L. cynari were collected in quarantine of imported artichokes. Chant (1963) argued that interceptions of organisms in quarantine pose problems in understanding their geographic distribution, given that they could have been introduced with the imported material (in this case, artichokes), but they could also have reached the material while en route or after its arrival to the final destination. He concluded that L. cynari should be specific to artichokes and should be common in Europe.

The characteristics of the adult females collected in Argentina agree well with those given in the original description of the species and observed in this study by the examination of type specimens. Artichoke cultivation began in Argentina in late 1800, with the arrival of Italian immigrants, who introduced the first cultivars and adapted them to local conditions of climate and soil (Sarli, 1958; Ávila, 1987). Thus, L .cynari, a paleartic species, may have been introduced to Argentina long ago. Lasioseius 


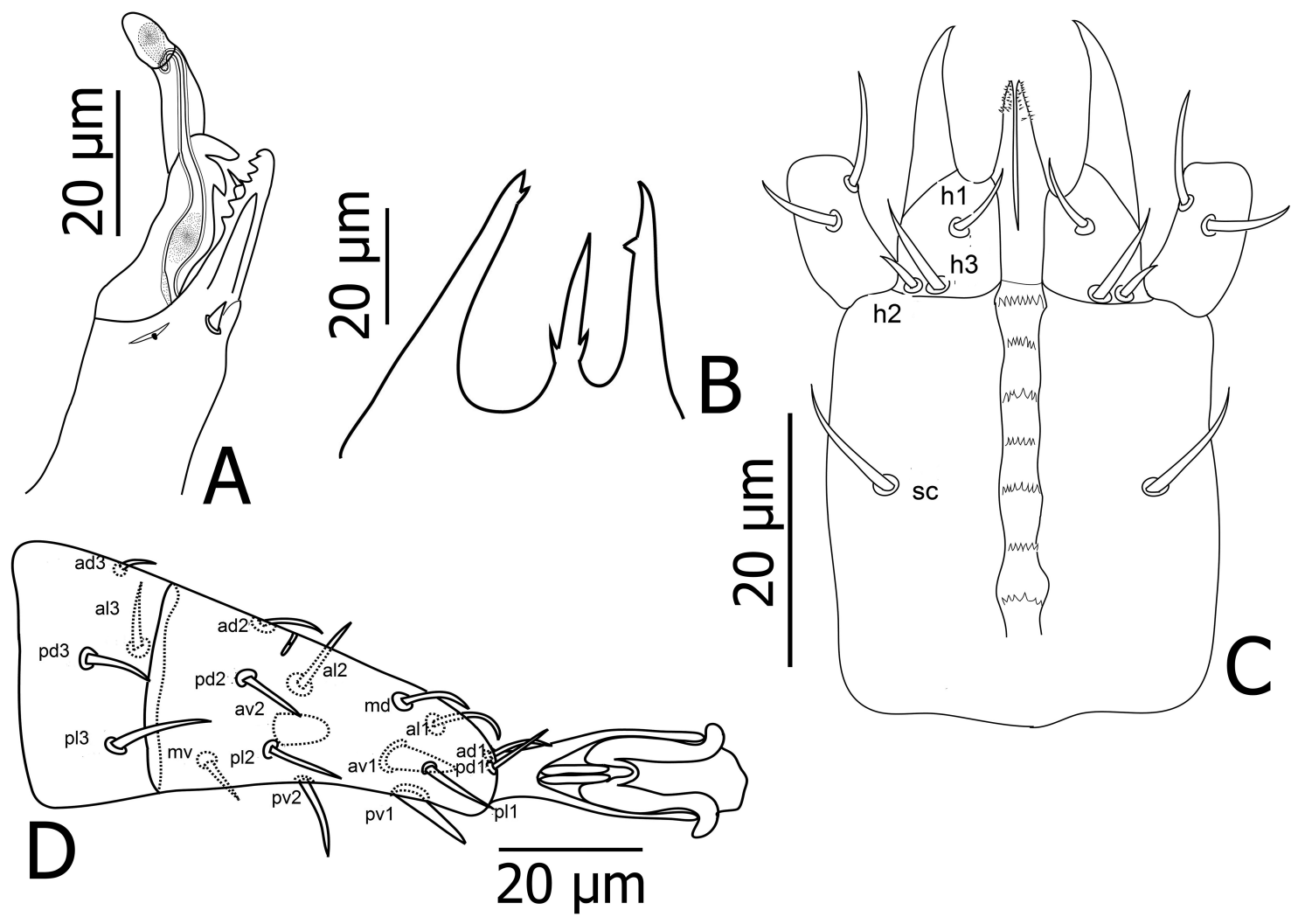

FIGURE 5: Lasioseius cynari, male: A - Chelicerae and spermatodactyl, B - Epistome, C - Ventral gnathosoma, D - Tarsus of leg II.

cynari seems to be a rare species on artichoke in Argentina, where only females were found. They seem to be specific to Cynara, the only genus onto which this species has been collected. Nothing is known about biology or ecology of this species, except that in Argentina it was found on leaves infested by the two spotted spider mites (Tetranychus urticae Koch, Tetranychidae), eriophyid mites (Aceria sp.), and aphids (Capitophorus elaeagni (Del Guercio), Aphididae).

This is the first report of this species after its original description, and it is the first record of this species on C. cardunculus.

\section{ACKNOWLEDGEMENTS}

We are especially grateful to Dr. E. E. Lindquist for the kindness and generosity to facilitate the examination of type specimens. To F. Beaulieu and W.
Knee for their technical support in this process. To J. C. Zembo for allowing us to collect these mites in his property. We thank the two reviewers who improved the manuscript with their comments.

This work was partially supported financially by Universidad Nacional de La Plata (UNLP), Argentina, and Consejo Nacional de Investigaciones Científicas y Tecnológicas, CONICET, Argentina.

\section{REFERENCES}

Ávila E. 1987 - El alcaucil o alcachofa. Planta hortícola y medicinal - El Ateneo Ed. pp. 135.

Chant D. 1963 - The subfamily Blattisocinae Garman (Aceosejinae Evans) (Acarina: Blattisocidae Garman) (Aceosejidae Baker and Wharton) in North America, with descriptions of a new species - Can. J. Zool., 41: 243-305. doi:10.1139/z63-025

Christian A., Karg W. 2006 - The predatory mite genus Lasioseius Berlese, 1916 (Acari, Gamasina) - Abh. Ber. Naturkundemuseums. Görlitz, 77: 99-250. 
Evans G.O. 1963 - Observations on the chaetotaxy of the legs in the free-living Gamasina (Acari: Mesostigmata) - Bull. br. Mus. nat. Hist. Zool., 10: 275-303. doi:10.5962/bhl.part.20528

Farrier M.H., Hennessey M.K. 1993 - Soil-inhabiting and free-living Mesostigmata (Acari: Parasitiformes) from North America. An annotated checklist with bibliography and index - North Carolina Agricultural Research Service, North Carolina State University, Raleigh, North Carolina, Technical Bulletin, 302: 1-408.

Karg W. 1980 - Die Raubmilbengattung Lasioseius Berlese, 1916 - Zoologische. Jb. Syst., 107: 344-367.

Lindquist E.E. 1964 - A Revision of Mites of the Subfamily Blattisociinae (Acarina: Blattisociidae) in America North of Mexico -Ph.D. Dissertation, University of California, Berkeley, $413 \mathrm{pp}$.

Lindquist E.E., Evans G.O. 1965 - Taxonomic concepts in the Ascidae, with a modified setal nomenclature for the idiosoma of the Gamasina (Acarina: Mesostigmata) - Mem. Entomol. Soc. Can., 47: 1-64. doi:10.4039/entm9747fv
Lindquist E.E. 1994 - Some observations on the chaetotaxy of the caudal body region of gamasine mites (Acari: Mesostigmata), with a modified notation for some ventrolateral body setae - Acarologia, 35: 323326.

Moraes G.J. de, Britto E.P.J., Mineiro J.L. de C., Halliday B. 2016 - Catalogue of the mite families Ascidae Voigts \& Oudemans, Blattisociidae Garman and Melicharidae Hirschmann (Acari: Mesostigmata) - Zootaxa, 4112: 299 pp.

Sarli A. 1958 - Tratado de Horticultura - Acmé Ed. Buenos Aires, pp. 454.

\section{COPYRIGHT}

$($ co) EY-NC-ND Cedola C.V. et al. Acarologia is under free license. This open-access article is distributed under the terms of the Creative Commons-BY-NC-ND which permits unrestricted non-commercial use, distribution, and reproduction in any medium, provided the original author and source are credited. 